\title{
The Placement of Esophageal Stents in Different Esophageal Disease Related Conditions-A Review
}

\author{
Qian Yu*, Sachin Mulmi, Yang Liu \\ Department of Gastroenterology, Zhongda Hospital Affiliated to South East University, Nanjing, China \\ Email: hyyq1972@163.com
}

Received 11 March 2016; accepted 24 April 2016; published 27 April 2016

Copyright (C) 2016 by authors and Scientific Research Publishing Inc.

This work is licensed under the Creative Commons Attribution International License (CC BY). http://creativecommons.org/licenses/by/4.0/

(c) (i) Open Access

\begin{abstract}
In the past, the esophagus diseases causing the patient to unable to intake oral diet such as esophageal strictures, leaks, tracheoesophageal fistulas, etc. were managed by surgical interventions and parenteral nutrition to meet the demand of the body. After the development of technique of stent placement in esopahgus, there was revolutionary change in the management of such conditions promoting patients to take diet orally and improve their nutritional status as well as quality of life. Different types of commercial stents are available in the market with their own pros and cons. Our aim of this study was to review the different stents being used currently in the clinical practice, comparing the stents on their therapeutic outcome and complications, optimal timing of removal of stents for benign conditions and the methods studied by different clinicians to lower the rate of complications and reinterventions.
\end{abstract}

\section{Keywords}

Esophageal Stents, Esophageal Strictures, Dysphagia, Stent Migration, Self Expandable Metal Stents

\section{Introduction}

Esophagus is considered to be in upper part of alimentary canal. The esophagus is a muscular tube, is located within the mediastinum of the thorax and passes through the diaphragm till the opening of the stomach (cardiac orifice) hence connecting the pharynx to the stomach measuring 20 to $24 \mathrm{~cm}$ in length [1]. Anatomically, it can be classified into: 1. Cervical part; 2. Thoracic part; 3. Abdominal part (Figure 1).

The cervical part lies anterior to the vertebrae and posterior to the trachea. The thoracic esophagus is located 


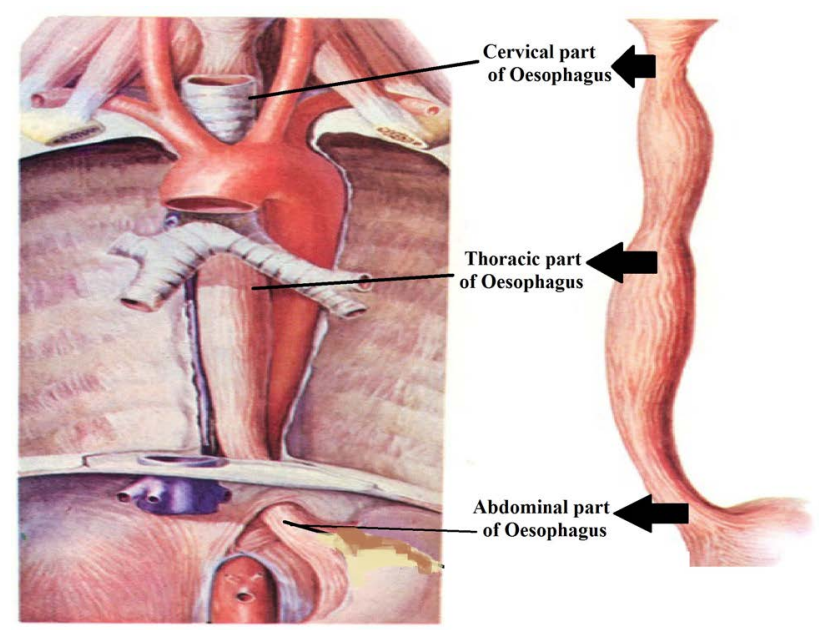

Figure 1. Illustrates the three parts of esophagus on basis of anatomy; cervical, thoracic and abdominal part. Source: anatomy department, NJMU.

adjacent to vital structures including the trachea, lungs, vertebrae, heart, blood vessels, and lymphatics and runs throughout in the posterior mediastinum. The length of abdominal part is usually $3 \mathrm{~cm}$ or less and connecting with the gastroesophageal junction (GEJ). The pathological lesions leading to different esophageal diseases range from a wide variety of squamous epithelial papillary hyperplasia to esophageal carcinoma. And these pathological lesions can lead to the esophageal strictures, tracheoesophageal fistula, acute perforations, leaks, etc. Disease progressions that can produce esophageal strictures can be categorized into three: 1) Diseases that lower esophageal sphincter (LES) function by their effects on esophageal smooth muscle and its innervation and/or disrupt esophageal peristalsis; 2) Extrinsic diseases - can narrow the esophageal lumen by direct invasion or lymph node enlargement; 3) Intrinsic diseases - can compromise the esophageal lumen through fibrosis, inflammation, or neoplasia [2]. Esopahgeal strictures can be divided into those with a malignant and benign origin [3]. Benign means that it is not caused by esophageal cancer.

Benign esophageal stricture can be caused by:

- Long-term use of a nasogastric (NG) tube

- Treatment of esophageal varices

- GERD-gastroesophageal reflux disease

- Eosinophilic esophagitis

- Injuries caused by an endoscope

- Swallowing substances that harm the lining of the esophagus. These may include household cleaners, battery acid, etc.

- Radiation injury

The cause of malignant esophageal strictures mainly account to primary esophageal cancer and also to other extra esophageal malignancies that compress the esophagus [3]. Stents are not the first-line choice for benign strictures but are reserved for patients who have failed other previous therapies. As in refractory strictures, dilation may not open the stricture at all, or the stricture may open but again closes within a short period of time [2].

\section{Esophageal Stents}

An esophageal stent is approximately $2 \mathrm{~cm}$ (3/4 inch) wide flexible mesh tube, placed through the constricted area of the esophagus to allow food and beverages to pass from the mouth to the stomach (as shown in Figure 2). The stent gently expands to hold the narrowed area of the esophagus open. As based on history, esophagel stents were first used in nineteenth century which gradually developed to be more compatible and advanced as decalcified ivory to boxwood and German Silver, to rigid plastic and latex to self expandable metal stents (SEMS) using stainless steel to now to the most commonly used stent material, nitinol. Lately, self-expandable plastic stents and biodegradable stents have been manufactured [4] (Table 1). 


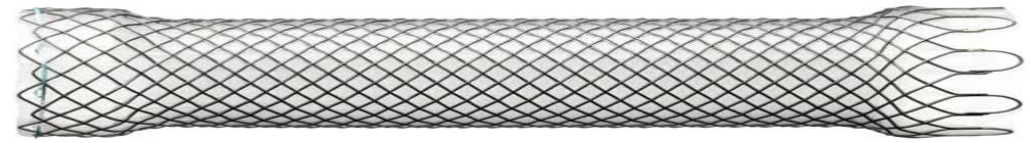

Figure 2. Wallflex esopahgeal stent (self expandable metal stent).

\section{Table 1. Types of esophageal stents based on.}

- Covering-(partially versus fully covered)

- Alloy material-(nitinol (alloy of 55\% nickel and 45\% titanium) versus surgical steel versus plastic polyvinyl),

- Function-(fully patent versus antireflux)

- Biodegradability

Source: [5].

\section{The Deployment of Stents in Different Esophageal Parts}

The main aim of insertion of esophageal stent in patients with advanced disease is to relieve dysphagia and to prevent associating malnutrition. The stent should specifically extend $2-4 \mathrm{~cm}$ beyond the lower ends of the stricture so as to minimize the chances of tumor overgrowth at the ends of the stent. The stents can be best placed in mid portion of esophagus i.e. thoracic part. Nevertheless, stents can also be placed in the distal esophagus (though with increased risk of regurgitation, gastric reflux and aspiration), and in the proximal esophagus (though the tumor must be more than $2 \mathrm{~cm}$ from the upper esophageal sphincter) [6]. A study by C. S. Shim, I. S. Jung, S. Bhandari et al., showed a newly designed SEMS with a short upper flange $(0.7 \mathrm{~cm}$ in length) was used in the treatment of proximal/cervical esophageal cancers in a small series of patients. Stent placement was successful in these patients with no serious complications [8].

\section{The Clinical Outcome of Stents Placement}

The placement of stents can effectively relieve the dysphagia improving the patient's quality of life. Maroju et al. placed Ultraflex nitinol self-expandable metallic stents endoscopically to 42 patients with malignant esophageal stricture. The quality-of-life score climbed from between 62 and 94 to between 80 and 133 in 30 patients. The dysphagia grade was also significantly improved [9]. In other study, Vakil and colleagues studied on 62 patients in a prospective, multicentric, randomized, controlled trial. Thirty patients with malignant inoperable esophageal obstruction at the gastroesophageal junction and 32 patients with comparable disease. Patients with malignant esophageal obstruction were treated with uncovered stents whereas other patients were treated with covered stents. One week after stenting the dysphagia scores improved similarly in both treatment arms [10]. In another study, R. Conigliaro, G. Battaglia, A. Repici et al. treated 60 patients with the Polyflex stent for malignant esophageal obstruction due to esophageal cancer $(n=52)$, lung cancer $(n=7)$, and thyroid tumor $(n=1)$. The mean dysphagia score of 2.8 improved to a mean score of 1.0 after stenting $(P<0.001)$ [11]. Another similar study by A. Eroglu et al. showed the results of 170 patients with 202 stents administered because of inoperable malignant esophageal stenosis and esophagorespiratory fistula between January 2000 and October 2008. Stent indications were advanced tumors with distant metastasis (82 cases, 48.2\%), unresectable tumors (51 cases, 30\%), patients who cannot tolerate surgery or chemoradiotherapy (18 cases, $10.5 \%)$, local recurrence after primary therapy (1 case, $0.5 \%$ ), esophagorespiratory fistulas from tumor or therapy (14 cases, $8.2 \%$ ), and refusal of surgery (4 cases, 2.3\%). Dysphagia scores evaluated by a modified Takita's grading system improved from 3.4 before the procedure to 2.6 afterward. The overall complication rate without chest pain was 31.7\% (occurring in 64 cases). Quality-of-life scores (The European Organization of Research and Treatment of Cancer QLQ C30) improved from $73 \pm 10.3(57-85)$ to $112 \pm 12.6(90-125)$ [12]. Ali A. Siddiqui et al. studied 55 patients in which tumors were located in the middle esophagus $(n=10)$ and distal esophagus $(n=45)$. The mean dysphagia score obtained at 1 week after stent placement had improved significantly from baseline $(2.4$ and 1 , respectively; P $<0.001)$. Patients maintained their weights at 1 month follow-up when compared with baseline (153 and 149 pounds, respectively; $\mathrm{P}<0.58$ ). Complications observed were chest discomfort in 13 patients; 2 patients required stent removal because of intractable pain, the stent had to be removed in 1 patient due to significant acid reflux, stent 
migration was seen at some point in 17 patients (31\%) and 1 patient had delayed perforation [13]. As the problem of dysphagia is relieved and the placement of stent widens the narrowing of the lumen of esophagus, patients become able to engulf the liquid and semi solid diets which also give the patients to sustain the nutritional status post disease as shown in Figure 3. In the past, patients with malignant strictures who could not intake the food or liquid due to dysphagia, nutritional support was given either by direct jejunostomy or nasogastric tubes. A multicenter trial evaluating patients receiving neoadjuvant therapy showed that half of the patients studied required nutritional support, either by direct jejunostomy or nasogastric tubes [14]. Another study by Sonawane RN, Thombare MM, Kumar A, et al., studied the patients undergoing neoadjuvant therapy. As surgical placement of jejunostomy tubes has long been the mainstay for obtaining enteral access who cannot consume an adequate caloric intake via oral route. Although this placement has distinct advantages over parenteral nutrition but can be complicated by dehiscence of the stomach with leakage of gastric contents, regurgitation of the jejunal tube to the stomach (increasing the risk of aspiration), peritonitis, gastric fistula, bleeding of the digestive tract, and withdrawal or obstruction of the tube [15]. After the concept of placement of esopahegeal stent came in to practice with therapeutic efficacy of relieving dysphagia and with lesser complications, the need of jejunostomy tube and parenteral nutrtion has been lowered day by day. Juan Carlos Martinez et al. concluded in their study that compared to parenteral nutrition, endoscopic stent placement can significantly improve a patient's quality of life by restoring the ability of intaking food and fluid orally compared to parenteral nutrition [6].

\section{Complications of Esophageal Stents}

Despite of successful relief of dysphagia initially by the stents, recurrent dysphagia can occur later due to migration of the stents as time passes or an ingrowth or overgrowth of the tumor. In a prospective trial by Knyrim and colleagues of 39 patients, the most common causes of recurrent dysphagia were shown to be migration of the plastic prostheses ( $n=5$ patients), or an ingrowth or overgrowth of the metal stents by tumor ( $n=5$ patients) [16]. The patients with esophageal cancers causing the stricture of esophagus developing the dysphagia have been benefited significantly from the combination of neoadjuvant therapy plus esophageal stents. The neoadjuvant therapy can minimize the tumor growth or even decrease the size of the tumor which might slower the deterioration of the patient's health condition. In a small study, by Lopes TL, Eloubeidi MA, demonstrated use of fully covered self expandable metal stents (FCSEMSs) can result in significant improvement in dysphagia over baseline by re-establishing esophageal luminal patency in patients undergoing neoadjuvant therapy for locally advanced esophageal cancer [17]. Bay and Penninga reported a case of inoperable distal esophageal adenocarcinoma and stented with a coated self expanding esophageal stent. Their patient underwent chemoradiotherapy and revealed good response to the treatment. Unfortunately, the decreased size of the tumor by chemoradiotherapy allowed the stent to migrate [18]. Although neoadjuvant therapy can improve symptoms of dysphagia
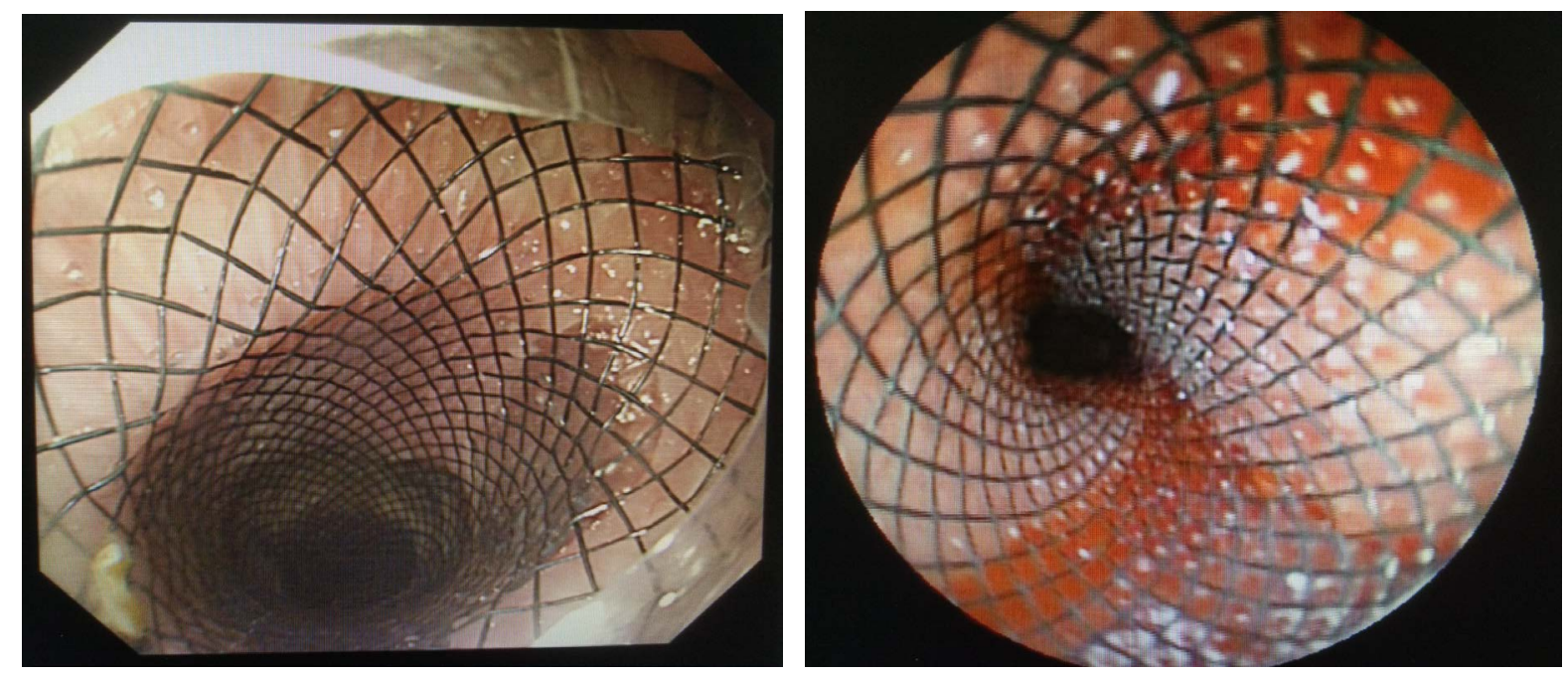

Figure 3. Self expandable metal stents seen through endoscopic view in 55 year old male with malignant esophageal stricture. Source: Endoscopic centre, Zhongda hospital. 
by decreasing tumor size and increasing the esophageal luminal diameter, most patients experience an initial worsening of the dysphagia as a result of mucositis [19]. This showed that the neoadjuvant therapy with stent placement though demonstrated good therapeutic effect in relieving dysphagia due to malignant strictures, recurrent dysphagia due to stent migration and mucosistis are the complications that have been seen in these patients.

The other common complications of stents are regurgitation, gastric reflux and aspiration, food obstruction, Tissue ingrowth and overgrowth, etc. The types of complications and degree of severity vary with different types of stents used and with the position of the stents placed. Among 60 patients, 32\% of patients manifested early minor complications (e.g., fever, gastroesophageal reflux symptoms, chest pain and incomplete usage of stent), while major complications (including 3 deaths, one occurring due to pulmonary embolism and two after massive hemorrhage) were seen in 22\%. Delayed stent migration occurred in 5 patients and tumor overgrowth occurred in 8 patients [11]. Apart from these complications, another faced problems by gastroenterologists or surgeon is bowel perforation due to stent migration. In a case report presented by Servet Karagul, et al., illustrated their patient had small bowel perforation as a consequence of a migrated esophageal stent who had a history of total gastrectomy with esophagojejunostomy [20]. Another study reported a case of esophagectomy and colon interposition. Six months later, stenosis in the cervical anastomosis was found and the authors implanted a silicon coated, wall stent. Six months later from the first stent, another stenosis was noted at the oral end of the stent and again second stent was inserted and two weeks later, they encountered the patient with small bowel perforation [21]. Similarly, another 4 studies also came up with similar reports [18] [22]-[24].

\section{Stent Comparison}

As there are myriads of esophageal stents available in the market as mentioned in Table 2., clinicians have been using these stents based on the indications, their clinical experiences and technical skills, costs of the different stents, length and position of the tumor, presence of a fistula, potential airway compromise and so on. Different studies have compared the different stents available in the market on different basis. In a study, authors found self expandable plastic stents (SEPS) are cumbersome to place and have a high migration rate because the stents are smooth, completely covered by a silicone membrane, and are without features designed to reduce migration [25]. Another study compared three stents, Ultraflex, Polyflex and Niti-S stents based on dysphagia improvement, comlications and tissue ingrowth and overgrowth after stent placement. Verschuur EM et al. in 2007 A.D. concluded the improvement of dysphagia and complications was similar for the three stents, but, overall, it was found that recurrent dysphagia occurred more frequently with Ultraflex ${ }^{\mathrm{TM}}$ stents $(\mathrm{n}=22[52 \%])$ than with Polyflex ${ }^{\circledR}$ stents $(n=15$ [37\%]) or Niti-S stents $(n=13$ [31\%]; $P=0.03)$. Of the main causes of recurrent dysphagia, stent migration was most commonly seen with Polyflex ${ }^{\circledR}$ stents $\left(\mathrm{n}=12[29 \%]\right.$ vs Ultraflex $^{\mathrm{TM}}$ stents: $\mathrm{n}=7$ [17\%] and Niti-S stents $n=5[12 \%])$. Tissue ingrowth and overgrowth was more frequent with Ultraflex ${ }^{\mathrm{TM}}$ stents $\left(n=13\right.$ [31\%] and, to a lesser degree, Niti-S stents $n=10$ [24\%] vs Polyflex ${ }^{\circledR}$ stents: $n=4$ [10\%]). Finally, food obstruction occurred frequently with Ultraflex ${ }^{\mathrm{TM}}$ stents $(\mathrm{n}=10[24 \%])$ vs Polyflex ${ }^{\circledR}$ stents $(\mathrm{n}=2$

Table 2. Commercially available stents in USA.

\begin{tabular}{llcccc}
\multicolumn{1}{c}{ Stent } & Material & Covering & Antireflux Valve & FDA Approved \\
\hline - & Esophageal Z & Stainless Steel & Fully/partially covered & Yes (dua variant) & Yes \\
- & Evolution & Nitinol & Partially covered & No & Yes \\
- Flamingo Wall stent & Stainless steel & Partially covered & No & No \\
- Gianturco Z & Stainless Steel & Partially covered & Yes & No & No \\
- & Niti-S & Nitinol & Fully/partially covered & Yes (PTFE variant) & Yes \\
- Polyflex & Polyester & Fully covered & No & Yes \\
- & Ultraflex NG & Nitinol & Not covered/partially & No & Yes \\
- Wallflex & Nitinol & Fully/partially covered & No & Yes \\
\hline
\end{tabular}

Source: [6]. 
[5\%]) vs Niti-S stents ( $n=1$ [2\%]) [26]. Apart from stent migration, another disadvantage of using Polyflex ${ }^{\circledR}$ stents is that the stent applicator is large and stiff compared with the applicators used for metallic stents. Therefore, dilation before stent placement is often required. Another drawback of using Polyflex® stents is the need to load the stent into the introduction catheter to avoid prolonged folding of the stent and prevent it from becoming deformed. For these reasons metal stents, particularly partially covered Ultraflex ${ }^{\mathrm{TM}}$ stents, are preferred to treat benign esophageal strictures, and retrieve the stents 4 - 6 weeks after placement. Ultraflex ${ }^{\mathrm{TM}}$ stents have the advantage that they are less likely to migrate than Polyflex ${ }^{\circledR}$ stents. For the deployment in cervical part, the best results can be obtained with the 10 or $12 \mathrm{~mm}$ cervical modified Niti-S stent types that are flared and fully covered for patients with complex hypopharyngeal strictures [3]. Another study by Conio et al. compared the self-expandable metal Ultraflex stent with the self-expandable plastic Polyflex stent in 100 patients with malignant esophageal disease. In another study, authors concluded despite the initial cost appears to be higher for metal stents but were ultimately more cost effective in overall because of the absence of fatal complications and the decrease in the hospital stay associated with their use [16]. The comparison concluded Covered SEMS as the treatment modality of choice for patients with malignant esophageal disease as a significant higher complication rate is seen in the plastic stent group [27]. So, the above studies directs towards the use of self expandable metal stents as the stent of choice than the self expandable plastic stents. SEPs have higher migration rate which can cause recurrent dysphagia and sometimes also bowel perforation. Clinicians have not only compared SEPs with SEMs but also SEMs available in the market manufactured by different manufacturers. Sabharwal et al. compared the SEMS Ultraflex stent with the Flamingo Wallstent, both showed similar efficacy in relieving malignant dysphagia and similar complication rates [28]. In another multicenter randomized clinical trial, 40 (50\%) Ultraflex stents and 40 (50\%) Evolution stents were placed. The reintervention rate was 15/40 (38\%) for the ultraflex stent and 4/39 (10\%) for the evolution stent $(\mathrm{P}=0.004)$. Reinterventions were needed to manage persistent dysphagia caused by incomplete expansion of the Evolution stent $(n=1)$, recurrent leakage $(n=1)$, stent migration $(n=4)$, tumoral tissue ingrowth or overgrowth $(n=9)$ or food obstruction $(n=7)$. Major complications included aspiration pneumonia and bleeding, occurred more frequently with the ultraflex stent (10/40, 25\%) than with the evolution stent $(3 / 39,8 \%, P=0.04)$ [29]. The complications are not only the troublesome for the clinicians but the need of reinterventions due to different complications also causes hindrance on the patient's symptoms recovery and also increasing treatment expenses. Comparison between uncovered and covered stents placed on 62 patients revealed tumor ingrowth was significantly more likely in the uncovered stent group (9/30) than in the covered group $(1 / 32)(P=0.005)$. Reinterventions for tumor ingrowth were also significantly greater in the uncovered stent group (27\%), as compared with $0 \%$ in the covered group $(\mathrm{P}=0.002)$ [10]. The study of the biodegradable stent in 2012, showed a favorable risk/benefit ratio, achieving complete relief of dysphagia in nearly $50 \%$ of recurrent benign esophageal stents (RBES) patients without the occurrence of major complications. The use of this stent may be a valuable alternative to repeat endoscopic dilation [30]. According to research presented at the Society of American Gastrointestinal and Endoscopic Surgeons 2012 Annual Scientific Session and Postgraduate Course, Biodegradable stents do not prevent high-grade stricture formation after circumferential mucosal resection of the esophagus. So, still biodegradable stents are being studied further for its efficacy and use.

\section{The Optimal Time of Stent Removal}

Not only the placement of stent is crucial in the management of strictures but also removal is also important factor to be considered. And also preferences of stents in easy removal and the removal timing have been discussed in differernt studies. After complete response to neoadjuvant therapy, the stent can be removed as the degree of stricture is reduced. Many literatures have emphasized the concept of removing stents before or at the time of surgery in these patients. Both Partially covered stents and Fully Covered Metal Stents (FCSEMSs) can be considered in this setting, FCSEMSs are much easier to remove (in either the near-term or the long-term future) via endoscopy and surgery. Although partially covered stent would be less likely to migrate when compared with a FCSEMS, but if a partially covered stent could not be removed in a patient with a complete response to neoadjuvant therapy, it might be problematic for the patient as stents are no longer needed. Furthermore, partially covered stents might be difficult to remove surgically in those patients who proceed to esophagectomy, and the stent could potentially interfere with the surgery if the stent could not be removed easily or removed at all. The study by Ali A. Siddiqui, discussed that because of poor surgical candidacy, disease pro- 
gression, or the discovery of metastasis after the initiation of neoadjuvant therapy, only 8 of 55 patients (15\%) underwent curative resection. This is a striking finding that has significant implications for patients diagnosed with locally advanced esophageal cancer with dysphagia and should impact considerations regarding treatment and outcomes at all stages in their care. Within the context of their study, the majority of stents ultimately functioned as just palliative therapy for malignant dysphagia rather than a bridge for surgery [13]. So this directs towards the fact that many patients with esophageal cancer inducing malignant esophageal stricture that when choosing the stents for malignant esophageal strictures receiving neoadjuvant therapy, some patients can never undergo surgery due to the further deterioration of health status, old age or developing some conditions that condraindicate the surgical candidancy. So, beforehand the clinicians should also keep in mind to choose the stents with less possibility of complications and longer patency.

Other indications of stent placing also include tracheoesophageal fistula, rupture, acute perforations or leaks as mentioned in Table 3. But Until now, it is still not certain which rupture or leak should be treated with stenting or primary surgery. Generally, Stenting has been proposed for ruptures or leaks that are smaller than $70 \%$ of the circumference whereas surgery has been proposed for larger ruptures or leaks [31]. During the study period of Richard K. Freeman and friends, 162 patients underwent esophageal stent placement for an acute perforation ( $n=117)$ or anastomotic leak $(n=45)$. The stents were removed in less than 28 days for an acute perforation, the complication rate was seemed to reduce independently by $39 \%$ (odds ratio, 0.61 ; $95 \%$ confidence interval, 0.54 to $0.78 ; \mathrm{P}<0.01$ ) whereas complication rate that was independently reduced by $56 \%$ (odds ratio, $0.44 ; 95 \%$ confidence interval, 0.38 to 0.69 ; $\mathrm{P}<0.001$ ) for an acute perforation whose stent was removed in less than 14 days after placement. Removal of stents at 2 weeks for anastomotic leak or 4 weeks for perforation may significantly decrease the incidence of complications [32]. Another study included total of 52 patients, received 83 esophageal stents (61 partial self expandable metal stents PSEMS, 15 fully self expandable metal stents (FSEMS), 7 self expandable plastic stents SEPS) for an anastomotic leak $(n=32)$, iatrogenic rupture $(n=13)$, Boerhaave's syndrome $(n=4)$ or other cause $(n=3)$. Except for eight patients treated with (PSEMS) for whom stents couldn't be removed due to tissue ingrowth, in other patients endoscopic Stent removal was successful. Clinical success was achieved in 34 (76\%, intention-to-treat: 65\%) patients (PSEMS: 73\%, FSEMS: 83\%, SEPS: 83\%) after a median of 1 (range 1 - 5) stent and a median stenting time of 39 (range 7 - 120) days. In total, 33 complications in $24(46 \%)$ patients occurred (tissue in- or overgrowth $(n=8)$, stent migration $(n=10)$, ruptured stent cover (all Ultraflex; $n=6$ ), food obstruction $(n=3)$, severe pain $(n=2)$, esophageal rupture $(n=2)$, hemorrhage $(n=2))$. One (2\%) patient died of a stent-related cause [33]. So, this study indicated the need of proper timing of removal of stents in patients with anastomotic leaks and perforations in order to reduce the complication rates hence also reducing the reintervention requirements. One Study in 2012 presented a concept of tandem esophageal stenting above the lower esophageal sphincter (LES) by taking advantage of the natural anatomical anchorage offered by the LES, with additional radial expansile force provided by the inner stent holding the outer stent in place. Tandem stenting was done for a bronchoes-ophageal fistula in 22 year girl as the first

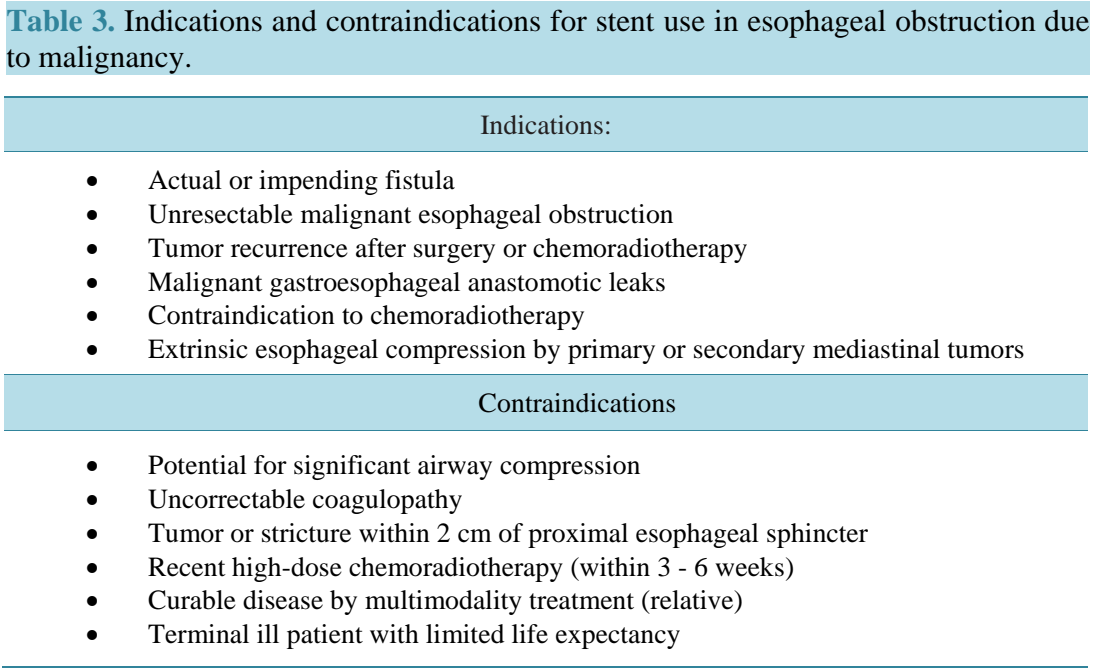

Source: [5] [7]. 
evolution stent was migrated to stomach after 2 days of deployment. So, tandem stenting was done by second evolution stent which allowed the first stent to hold in the place and a girl was able to take oral diet [34]. So, this concept of tandem stenting showed the major complication of stent migration can be reduced which is seen in all the stents available in the market.

\section{Conclusion}

In today's world, the esophageal stenting has been accepted as one of the important treatment modality for the management of various esopahageal conditions. It has been seen successful in managing benign and malignant strictures of esophagus, tracheoesophageal fistula, acute perforations, leaks and so on. Specially, it is very beneficial for the patients with malignant strictures receiving neoadjuvant therapy. The objective of stent placement is to hold the stricture open for prolonged periods of time, causing the stricture, or the tissue around it to remodel so that the stricture does not recur when the stent is removed. For the disease related esophageal conditions with indications of need of stenting, though myriads of stents are commercially available in the market, FCSEMs have been seen as the most effective one to treat the esophageal conditions with fewer complications and also the need of reinterventions are lesser in covered stents than in uncovered stents. The new concept of esophageal stents with biodegradability has still been in studies to find its benefit to other stents. Although the stents have been successful in relieving dysphagia improving the patient's oral intake and quality of life but the stent migration is seen to be the major problem, also recurrent dysphagia, acid reflux and other complications are frequently encountered. Tandem stenting has also been proposed by few as the other method to decrease the complication. So, we encourage further studies to be performed in newly developed stents and in new concepts about techniques to deploy the stents so that its clinical benefit can be much widened and the complications can be decreased.

\section{References}

[1] Jang, K.M., Lee, K.S., Lee, S.J., Kim, E.A., Kim, T.S., Han, D., et al. (2002) The Spectrum of Benign Esophageal Lesions: Imaging Findings. Korean Journal of Radiology, 3, 199-210. http://dx.doi.org/10.3348/kjr.2002.3.3.199

[2] Baron, T.H. (2011) Management of Benign Esophageal Strictures. Gastroenterology \& Hepatology, 7, 46-49.

[3] Siersema, P.D. (2008) Treatment Options for Esophageal Strictures. Nature Clinical Practice Gastroenterology \& Hepatology, 5, 142-152. http://dx.doi.org/10.1038/ncpgasthep1053

[4] Kozarek, R.A., Baron, T.H. and Song, H.-Y. (2013) Self-Expandable Stents in the Gastrointestinal Tract. Springer, New York, 310 p. http://dx.doi.org/10.1007/978-1-4614-3746-8

[5] Baerlocher, M.O., Asch, M.R., Dixon, P., Kortan, P., Myers, A., Law, C., et al. (2008) Interdisciplinary Canadian Guidelines on the Use of Metal Stents in the Gastrointestinal Tract for Oncological Indications. Canadian Association of Radiologists Journal (Journal l'Association Canadienne des Radiologistes), 59,107-122.

[6] Martinez, J.C., Puc, M.M. and Quiros, R.M. (2011) Esophageal Stenting in the Setting of Malignancy. ISRN Gastroenterology, 2011, Article ID: 719575. http://dx.doi.org/10.5402/2011/719575

[7] Katsanos, K., Sabharwal, T. and Adam, A. (2010) Stenting of the Upper Gastrointestinal Tract: Current Status. CardioVascular and Interventional Radiology, 33, 690-705. http://dx.doi.org/10.1007/s00270-010-9862-6

[8] Shim, C.S., Jung, I.S., Bhandari, S., Ryu, C.B., Hong, S.J., Kim, J.O., et al. (2004) Management of Malignant Strictures of the Cervical Esophagus with a Newly-Designed Self-Expanding Metal Stent. Endoscopy, 36, 554-557. http://dx.doi.org/10.1055/s-2004-814555

[9] Maroju, N.K., Anbalagan, P., Kate, V. and Ananthakrishnan, N. (2006) Improvement in Dysphagia and Quality of Life with Self-Expanding Metallic Stents in Malignant Esophageal Strictures. Indian Journal of Gastroenterology: Official Journal of the Indian Society of Gastroenterology, 25, 62-65.

[10] Vakil, N., Morris, A.I., Marcon, N., Segalin, A., Peracchia, A., Bethge, N., et al. (2001) A Prospective, Randomized, Controlled Trial of Covered Expandable Metal Stents in the Palliation of Malignant Esophageal Obstruction at the Gastroesophageal Junction. The American Journal of Gastroenterology, 96, 1791-1796. http://dx.doi.org/10.1111/j.1572-0241.2001.03923.x

[11] Conigliaro, R., Battaglia, G., Repici, A., De Pretis, G., Ghezzo, L., Bittinger, M., et al. (2007) Polyflex Stents for Malignant Oesophageal and Oesophagogastric Stricture: A Prospective, Multicentric Study. European Journal of Gastroenterology \& Hepatology, 19, 195-203. http://dx.doi.org/10.1097/MEG.0b013e328013a418

[12] Eroglu, A., Turkyilmaz, A., Subasi, M. and Karaoglanoglu, N. (2010) The Use of Self-Expandable Metallic Stents for 
Palliative Treatment of Inoperable Esophageal Cancer. Diseases of the Esophagus, 23, 64-70. http://dx.doi.org/10.1111/j.1442-2050.2009.00978.x

[13] Siddiqui, A.A., Sarkar, A., Beltz, S., Lewis, J., Loren, D., Kowalski, T., et al. (2012) Placement of Fully Covered Self-Expandable Metal Stents in Patients with Locally Advanced Esophageal Cancer before Neoadjuvant Therapy. Gastrointestinal Endoscopy, 76, 44-51. http://dx.doi.org/10.1016/j.gie.2012.02.036

[14] Belghiti, J., Langonnet, F., Bourstyn, E. and Fekete, F. (1983) Surgical Implications of Malnutrition and Immunodeficiency in Patients with Carcinoma of the Oesophagus. The British Journal of Surgery, 70, 339-341. http://dx.doi.org/10.1002/bjs.1800700610

[15] Sonawane, R.N., Thombare, M.M., Kumar, A., Sikora, S.S., Saxena, R., Kapoor, V.K., et al. (1997) Technical Complications of Feeding Jejunostomy: A Critical Analysis. Tropical Gastroenterology, 18, 127-128.

[16] Knyrim, K., Wagner, H.J., Bethge, N., Keymling, M. and Vakil, N. (1993) A Controlled Trial of an Expansile Metal Stent for Palliation of Esophageal Obstruction Due to Inoperable Cancer. The New England Journal of Medicine, 329, 1302-1307. http://dx.doi.org/10.1056/NEJM199310283291803

[17] Lopes, T.L. and Eloubeidi, M.A. (2010) A Pilot Study of Fully Covered Self-Expandable Metal Stents Prior to Neoadjuvant Therapy for Locally Advanced Esophageal Cancer. Diseases of the Esophagus, 23, 309-315. http://dx.doi.org/10.1111/j.1442-2050.2009.01011.x

[18] Bay, J. and Penninga, L. (2010) [Small Bowel Ileus Caused by Migration of Oesophageal Stent]. Ugeskr Laeger, 172, 2234-2235.

[19] Diaz, R., Reynes, G., Tormo, A., de Juan, M., Girones, R., Segura, A., et al. (2009) Long-Term Results of Neoadjuvant Chemotherapy and Combined Chemoradiotherapy before Surgery in The management of Locally Advanced Oesophageal Cancer: A Single-Centre Experience. Clinical \& Translational Oncology, 11, 835-841. http://dx.doi.org/10.1007/s12094-009-0452-5

[20] Karagul, S., Yagci, M.A., Ara, C., Tardu, A., Ertugrul, I., Kirmizi, S., et al. (2015) Small Bowel Perforation Due to a Migrated Esophageal Stent: Report of a Rare Case and Review of the Literature. International Journal of Surgery Case Reports, 11, 113-116. http://dx.doi.org/10.1016/j.ijscr.2015.04.030

[21] Henne, T.H., Schaeff, B. and Paolucci, V. (1997) Small-Bowel Obstruction and Perforation. A Rare Complication of an Esophageal Stent. Surgical Endoscopy, 11, 383-384. http://dx.doi.org/10.1007/s004649900369

[22] Zhang, W., Meng, W.J. and Zhou, Z.G. (2011) Multiple Perforations of the Jejunum Caused by a Migrated Esophageal Stent. Endoscopy, 43, E145-E146.

[23] Reddy, V.M., Sutton, C.D. and Miller, A.S. (2009) Terminal Ileum Perforation as a Consequence of a Migrated and Fractured Oesophageal Stent. Case Reports in Gastroenterology, 3, 61-66. http://dx.doi.org/10.1159/000210542

[24] Kim, H.C., Han, J.K., Kim, T.K., Do, K.H., Kim, H.B., Park, J.H., et al. (2000) Duodenal Perforation as a Delayed Complication of Placement of an Esophageal Stent. Journal of Vascular and Interventional Radiology, 11, 902-904. http://dx.doi.org/10.1016/S1051-0443(07)61809-0

[25] Costamagna, G., Shah, S.K., Tringali, A., Mutignani, M., Perri, V. and Riccioni, M.E. (2003) Prospective Evaluation of a New Self-Expanding Plastic Stent for Inoperable Esophageal Strictures. Surgical Endoscopy, 17, 891-895. http://dx.doi.org/10.1007/s00464-002-9098-X

[26] Verschuur, E.M., Repici, A., Kuipers, E.J., Steyerberg, E.W. and Siersema, P.D. (2008) New Design Esophageal Stents for the Palliation of Dysphagia from Esophageal or Gastric Cardia Cancer: A Randomized Trial New Esophageal Stent Designs for Malignant Dysphagia. The American Journal of Gastroenterology, 103, 304-312. http://dx.doi.org/10.1111/j.1572-0241.2007.01542.x

[27] Conio, M., Repici, A., Battaglia, G., De Pretis, G., Ghezzo, L., Bittinger, M., et al. (2007) A Randomized Prospective Comparison of Self-Expandable Plastic Stents and Partially Covered Self-Expandable Metal Stents in the Palliation of Malignant Esophageal Dysphagia. The American Journal of Gastroenterology, 102, 2667-2677. http://dx.doi.org/10.1111/j.1572-0241.2007.01565.X

[28] Sabharwal, T., Hamady, M.S., Chui, S., Atkinson, S., Mason, R. and Adam, A. (2003) A Randomised Prospective Comparison of the Flamingo Wallstent and Ultraflex Stent for Palliation of Dysphagia Associated with Lower Third Oesophageal Carcinoma. Gut, 52, 922-926. http://dx.doi.org/10.1136/gut.52.7.922

[29] van Heel, N.C., Haringsma, J., Boot, H., Cats, A., Vanhoutvin, S.A. and Kuipers, E.J. (2012) Comparison of 2 Expandable Stents for Malignant Esophageal Disease: A Randomized Controlled Trial. Gastrointestinal Endoscopy, 76, 52-58. http://dx.doi.org/10.1016/j.gie.2012.02.050

[30] Repici, A., Vleggaar, F.P., Hassan, C., van Boeckel, P.G., Romeo, F., Pagano, N., et al. (2010) Efficacy and Safety of Biodegradable Stents for Refractory Benign Esophageal Strictures: the BEST (Biodegradable Esophageal Stent) Study. Gastrointestinal Endoscopy, 72, 927-934. http://dx.doi.org/10.1016/j.gie.2010.07.031

[31] Schubert, D., Scheidbach, H., Kuhn, R., Wex, C., Weiss, G., Eder, F., et al. (2005) Endoscopic Treatment of Thoracic 
Esophageal Anastomotic Leaks by Using Silicone-Covered, Self-Expanding Polyester Stents. Gastrointestinal Endoscopy, 61, 891-896. http://dx.doi.org/10.1016/S0016-5107(05)00325-1

[32] Freeman, R.K., Ascioti, A.J., Dake, M. and Mahidhara, R.S. (2015) An Assessment of the Optimal Time for Removal of Esophageal Stents Used in the Treatment of an Esophageal Anastomotic Leak or Perforation. The Annals of Thoracic Surgery, 100, 422-428. http://dx.doi.org/10.1016/j.athoracsur.2015.03.085

[33] van Boeckel, P.G., Dua, K.S., Weusten, B.L., Schmits, R.J., Surapaneni, N., Timmer, R., et al. (2012) Fully Covered Self-Expandable Metal Stents (SEMS), Partially Covered SEMS and Self-Expandable Plastic Stents for the Treatment of Benign Esophageal Ruptures and Anastomotic Leaks. BMC Gastroenterology, 12, 19. http://dx.doi.org/10.1186/1471-230X-12-19

[34] Tang, S.J., Singh, S., Wait, M.A., Mullican, M.A. and Scott, D.J. (2009) Endotherapy for a 5-cm Mid-Esophageal Perforation with Tandem Stenting above the Lower Esophageal Sphincter (with Videos). Surgical Endoscopy, 23, 28362841. http://dx.doi.org/10.1007/s00464-009-0485-4

\section{Abbreviations}

* Nasogastric (NG) tube

* GERD-gastroesophageal reflux disease

* Gastroesophageal junction (GEJ)

* Lower esophageal sphincter (LES)

* Self expandable metal stents (SEMS)

* Fully covered Self expandable metal stents (FCSEMSs)

* Self expandable plastic stents (SEPS)

* Partial self expandable metal stents PSEMS 